\title{
Depression, Anxiety, and Stress During Times of COVID-19: An Analysis of Youngsters Studying in Higher Education in India
}

\author{
Hemraj Verma ${ }^{1} \cdot$ Garima Verma $^{2}$ (D) Pankaj Kumar ${ }^{1}$
}

Received: 28 May 2021 / Accepted: 8 September 2021 / Published online: 27 September 2021

(c) Springer Japan KK, part of Springer Nature 2021

\begin{abstract}
This study addressed the critical problems of depression, anxiety, and stress, which are prevalent among students pursuing higher education. Specifically, this article aimed to study the level of psychological distress due to the COVID-19 pandemic experienced by young people studying in higher education institutions in India. The study also attempted to identify various coping strategies students adopted to overcome this difficult time. Following a descriptive research design, this study used surveys to collect primary data from 235 students in graduate and undergraduate programs in India. The DASS-21 scale was used to check the levels of depression, anxiety, and stress students experienced. Furthermore, a four-point COPE scale was used to identify coping strategies students adopted. The results showed that students experienced high levels of stress and anxiety during the ongoing COVID-19 pandemic. Although depression levels were not alarming, most students were worried about several aspects of their lives and careers. However, because the data were collected from a relatively small sample, the study is likely not generalisable. Furthermore, most of the data were collected online, which has its limitations. This research likely has significant implications for various stakeholders, such as students, parents, institutions, counsellors, and government and non-government bodies, because it may help them take appropriate actions. These research contributions are original and novel, because the COVID-19 pandemic has posed unprecedented challenges and inspired new solutions to the problems of students and society.
\end{abstract}

Garima Verma

garimaverma.research@gmail.com

Hemraj Verma

drhemraj.verma@ dituniversity.edu.in

Pankaj Kumar

pankaj.kumar@dituniversity.edu.in

1 DMS, DIT University, Dehradun, India

2 School of Computing, DIT University, Dehradun, India 
Keywords Depression $\cdot$ Anxiety $\cdot$ Stress $\cdot$ COVID-19 $\cdot$ Coping strategies

\section{Introduction}

The world is in the midst of the coronavirus disease (COVID-19) crisis that has disrupted lives across the globe. COVID-19 is believed to have originated from Wuhan, China, in December 2019 and has now spread to countries around the world [1]. With 40,665,438 confirmed COVID-19 cases and 1,121,843 lakh deaths as of 21 October 2020, the situation has rightly been declared a pandemic according to the 'WHO Coronavirus Disease (COVID-19) Dashboard', 2020 [2]. In addition to the loss of human life, most businesses and non-business activities have been shut down, causing short-term disruptions. A few industries, such as tourism and related services, have been hit so badly that it may take years to return to normal. This pandemic has changed the way people, societies, and businesses think and function.

Like most business organizations, educational institutions have been affected adversely by COVID-19 [2]. Globally, the pandemic has affected almost $90 \%$ of the student population (1.2 billion). To ensure the safety and security of students, teachers, and other staff, there has been a global shutdown of education activities. Although UNESCO, working with ministries around the world, has tried to ensure that education continues by suggesting education take place through online platforms, the disruptions across the education sector are apparent. Most institutions were caught off guard and were unprepared to deal with the large-scale adverse impacts of the pandemic. Remote education in virtual classrooms has been a disorienting experience for students, and parents struggled to motivate their wards and children to attend online classes, impacting their own productivity [3, 4].

Although a report from the World Economic Forum [5] suggested that online learning results in increased retention and understanding of information, its efficacy and effectiveness has yet to be confirmed globally. The situation in India has been more or less the same. Most school-level examinations, board examinations, yearly higher education examinations, and other important entrance examinations that are gateways to niche medical and engineering institutions have been postponed or canceled. The Ministry of Human Resource Development, a department in the Indian government, has occasionally issued guidelines for conducting online classes and administering exams, but has failed to offer a concrete solution as the number of COVID-19 cases continues to rise in India [4].

The pandemic has been toughest for students who are pursuing their final semester or year of their higher education, as many have lost employment opportunities or their hiring has been deferred for an undetermined amount of time. Furthermore, others could not pursue internships, and uncertainty about their immediate future looms large. To complicate matters further, all universities and other private institutions have continued asking for tuition payments when most have failed to deliver effective education as promised. All these events appear to have caused anxiety, stress, and depression among the students [3, 4].

The COVID-19 pandemic protocol requiring strict isolation has forced learners and educators to be confined in their homes. The disruption to their social lives and 
learning in isolation has created stress for students and educators. Educators and students are missing out on the essence of group learning and classroom activities, creating stress for both groups. People attempt to overcome the negative impacts of a lack of physical activity and spending all one's time at home by employing other activities as coping mechanisms. People of all age groups and socioeconomic backgrounds are suffering from depression around the world, including in India. At the global level, approximately 322 million people were affected by depression (World Health Organization 2020) [6]. Depression influences one's quality of life, creating enormous economic and social burdens at the individual, family, national, and global levels. In India, almost 1 in 20 people over 18 suffered the consequences of depression at one time (National Mental Health Survey of India, 2015-16, 2016) [6]. Furthermore, nearly 45 million people were diagnosed with depressive syndrome in 2015 , and approximately 2.6 million $(22.5 \%$ ) people globally will be affected by depression due to population expansion and aging by 2025 [7].

\section{Literature Review}

\subsection{Stress}

One factor that hinders human functioning is stress. Broadly, stress can be understood as 'the physiological and emotional changes brought on by stress hormones (such as adrenaline, noradrenaline and cortisol) in response to certain situational or event stressors' $[6,7]$. Research on stress has received much attention from academics and practitioners, especially in the last 2 decades as people's stress has increased. In an organizational context, research has focused on investigating the impact of stress on employee health, well-being, and behavior [8].

Stress has received research attention in the last 50 years [9]. As work relationships, value systems, personal ambitions, and social expectations have evolved, the sources of stress have also evolved [10]. Researchers are continually exploring mechanisms that can help individuals' better cope with stress. As the sources of stress change and increase, individuals' various stress symptoms must be examined [11].

Early definitions described stress as a reaction to stimuli from the environment. Selye's (1973) physiological model conceptualized stress as a general reaction to toxic stimuli independent of the existence of the stressor or characteristics of the stressed person [12]. Stress is seen by the related general adaptation syndrome as progressing through warning, resistance, and fatigue stages that could ultimately harm one's physiological system by disrupting equilibrium [12]. More recent research defines stress as the process of interrelation between a person and the environment, hence the specific response of individuals to environmental demands and pressures. Stress was defined by [13] as an active, unfolding process consisting of causal antecedents, mediating processes, and effects. A broad body of research on stress and stressful life events has shown that stress can be an important part of life. Moreover, tension is not uniformly negative for everyone. Research has emphasized 
that errors, hurdles, and setbacks are potential opportunities for learning and developing the capacity to deal with possible adverse events $[14,15]$.

Stress is an inevitable part of everyone's life, including students, who must experience different types of crises throughout their education. For example, adjusting to a new campus environment, relationships with classmates and teachers, and course assessments can all cause stress [11]. However, these factors have become even more complicated due to the ongoing pandemic, which has created uncertainty regarding effective teaching, learning, assessments, and adapting to a new online environment.

\subsection{Anxiety}

Anxiety disorders are among the most prevalent mental health problems in personal life. Anxiety is a general emotion that motivates a person to work hard and improve. If the anxiety is simple, it is briefly acute before receding and does not interfere with everyday life. In modern times, everyone feels anxious occasionally, but anxiety becomes a disorder when anxious feelings persist for a long time. An anxiety disorder is more than feeling stressed or anxious: it stops people from doing things they enjoy. Anxiety is a normal reaction under pressure, and a person may feel anxious before making any important decision [14]. Found that anxiety is a widespread problem for many students who are so distraught by the stress associated with testtaking that they experience a substantial decline in performance during tests, and their performance in evaluation conditions declines.

Although stress is typically not a symptom of a more organized anxiety or depressive disorder, it can be a precursor to these problems. Depression and anxiety are common in medical education [16, 17], and several studies have recorded high anxiety levels among medical students $[10,16,17]$. Some observational evidence has shown that women are more vulnerable to anxiety disorders than men, citing a marginally greater incidence of anxiety disorders [17, 18]. Nevertheless, [18] found no significant gender differences among medical students on measures of depression. In general, studies indicate greater levels of anxiety for female medical students compared with their male counterparts.

\subsection{Depression}

Depression is a mental disorder involving symptoms such as hopelessness, despair, inadequacy, low self-esteem, lack of energy, worthlessness, self-depreciation, and reduced interest in life. Depression is associated with a low probability of achieving something significant in life and may lead to poor health and suicidal tendencies in people with depression [9, 19, 20]. Depression, also called clinical depression, is a common and serious medical illness that leads to negative feelings and can change how a person thinks and acts. This disorder can cause various emotional and physical issues and can also decrease people's capacity to work, hindering their daily activities and resulting in reduced time and productivity. It can also affect relationships and some chronic health conditions $[19,20]$. 
A study by [21] indicated that people in China experienced serious psychological distress such as stress, anxiety, and depression due to the COVID-19 pandemic. Likely, the situation in other countries is no different. Thus, it is plausible to assume that COVID-19 created a fear of the unknown, as very little was known about the nature of the virus then, and led to feelings of anxiety, stress, and depression in all people, including students. The pandemic has certainly impacted the mental wellbeing of all people, and students are likely to experience it more severely, because they are young and have exciting lives ahead of them. Timely action addressing the mental health impacts of the COVID-19 pandemic is necessary [21]. Some even fear that COVID-19 may lead to suicide [22, 23]. Therefore, it is important to evaluate and address these mental health impacts, as they will likely lead to psychological issues [2].

\subsection{Coping Strategies}

Coping strategies are the methods people use to mitigate their anxiety, stress, and depression. These may include thought processes, behaviors, and emotional regulation strategies. In other words, coping strategies are simply mechanisms that help individuals tackle stressful situations. These mechanisms can include behavioral, physical, external, emotional, spiritual, and cognitive strategies [13, 24, 25].

Stressful events in the lives of university students generally include anxiety over exam performance, fear of failure, romantic relationships, career choices and bullying by older students, and students resort to a variety of strategies to cope with these stressors. These coping strategies may include good time management, seeking social support, distracting oneself by watching sport or movies, playing or listening to music, venting, problem-solving, self-reliance, and optimistic appraisal [26, 27]. Coping may also depend on relationships and contexts. Good relationships with family and friends may help students deal with stressful and depressive situations in a better way. Also, having a good psychological balance may help students better cope with distressing events [28].

\section{Research Gap and Objectives}

Stress is expected during a student's life [11], and moderate levels of stress may be beneficial to a student's life achievements [29]. However, extreme levels of stress may cause feelings of anxiety, depression, and other psychological disorders among students [11, 29]. There is abundant literature on students' academic and non-academic stressors and the sources of stress in university [30-33]. However, psychological issues such as anxiety, stress, and depression caused by COVID-19 are unprecedented, creating an interesting research gap due to the complexity and challenges of the pandemic and its impact on students. Therefore, it is critical to assess students' perceptions, feelings, and mental health in these challenging times.

In light of the above, the current study made a fresh investigation into the body of knowledge on anxiety, stress, and depression experienced by young people pursuing 
higher education. Likely, the severity of these mental health issues has increased significantly due to the COVID-19 pandemic.

This study had three key objectives:

(i) To investigate the level of stress, anxiety, and depression experienced by students pursuing higher education and determine whether these levels were similar or different in students of different genders and years of study.

(ii) To determine the most common stressors experienced by students.

(iii) To identify the coping strategies adopted by students in this time of heightened mental distress.

\section{Hypothesis Formulation}

Different socio-demographic groups experience different levels of stress [34-36]. However, the existence of gender differences in the experience of stress is inconclusive based on previous studies. For instance, one study by [35] indicated that females are more likely to perceive higher stress levels than males. Yet, a different study found that males experienced more stress [37, 38]. In yet another study, females reported a higher level of perceived stress than males [39]. Therefore, there will likely be variability in perceived stress among male and female students in higher education, especially during the pandemic when stress levels are likely higher due to the uncertain environment.

Similarly, studies have found that depression is more common in females than males [40]. For instance, the Global Burden of Disease report estimated the point prevalence of unipolar depressive episodes to be $1.9 \%$ for men and $3.2 \%$ for women and the 1-year prevalence to be $5.8 \%$ for men and $9.5 \%$ for women [41]. Furthermore, the burden of depression will increase to $5.7 \%$ of the total burden of disease, making it the second leading cause of disability in the world by 2020 . Also, some test anxiety studies found that the level of test anxiety was higher in female students than in male students [42]. Based on the literature, the following can be inferred:

Hypothesis 1 The levels of stress, anxiety, and depression among students pursuing higher education will vary significantly between male and female students.

Students experience different levels of stress, anxiety, and depression during different years of study because of the differing degrees of uncertainty associated with the institution's environment. For example, when students are first admitted, they are new to the campus environment, and the uncertainty will likely cause stress and anxiety. However, as they become familiar with the processes and environment of the campus, there are likely to feel more comfortable. However, stress and anxiety might increase once students reach their final or penultimate year, as students may start appearing in campus drives as they become more conscious of their future careers and lives. Some studies reported that younger students perceived more stress [35]. Therefore, the second hypothesis was proposed: 
Hypothesis 2 The levels of stress, anxiety, and depression among students pursuing higher education will vary significantly between students studying in different years.

People vary in how they respond to different life events [43]. For example, women and men experience different levels of stress, anxiety, and depression, and therefore are likely to respond differently in a given crisis situation. Moreover, there are likely gender differences in the methods people adopt to deal with stressful situations. Thus, it is plausible to assume that male and female students might use different methods to deal with stress, anxiety, and depression during the COVID-19 pandemic. In light of this information, the third hypothesis was proposed:

Hypothesis 3 Male and female students vary significantly in the coping strategies they employ to deal with stress, anxiety and depression.

\section{Research Methodology}

\subsection{Research Design and Sampling}

This study used a descriptive research design to achieve the stated objectives. To collect the primary data, a structured questionnaire was developed. A Google form containing the questionnaire was emailed to 1500 randomly chosen students from an email database containing 2443 students pursuing higher education (MBA, MCA, B.Tech, BBA, M.Tech,) in five institutions in the Dehradun region. Overall, the response rate was approximately $19 \%$, with only 289 forms submitted as filled forms. After subsequent screening, 45 questionnaires were found to be incomplete and were excluded from further analysis. Therefore, only 235 fully completed questionnaires were suitable for final analysis.

\subsection{Instrument Development}

\subsubsection{Instrument for Measuring Depression, Anxiety, and Stress}

A large part of the questionnaire was designed primarily using a standard psychometric scale called the Depression Anxiety Stress Scale (DASS-21), a short, valid scale derived from the full DASS-42 scale [44]. This scale has seven items for measuring stress, anxiety, and depression. It is a four-point scale ranging from 0 to 3 , with 0 indicating 'Did not apply to me at all or never', 1 indicating 'Applied to me some degree or sometimes', 2 indicating 'Applied to me to a considerable degree or good part of the times', and 3 indicating 'Applied to me very much or most of the time'.

The scores for various levels of depression, anxiety, and stress constructs are shown in Table 1. 
Table 1 Scores for various levels of depression, anxiety, and stress

\begin{tabular}{llll}
\hline Severity & Depression & Anxiety & Stress \\
\hline Normal & $0-9$ & $0-7$ & $0-14$ \\
Mild & $10-13$ & $8-9$ & $15-18$ \\
Moderate & $14-20$ & $10-14$ & $19-25$ \\
Severe & $21-27$ & $15-19$ & $26-33$ \\
Extremely severe & $28+$ & $20+$ & $34+$ \\
\hline
\end{tabular}

\subsubsection{Instrument for Identifying Causes of Stress}

A 17-item questionnaire was used to analyze the causes of stress. It employed a four-point Likert scale ranging from 'Strongly disagree (score 1)' to 'Strongly agree (score 4)' to score each item. The stressors used in the questionnaire were derived from reviewing the literature and holding a discussion with a group of students.

The second part of the questionnaire consisted of items measured on a fivepoint Likert-type scale, which was used to identify the most common causes of stress for students. The statement used was 'I feel —— has been the most frequent stressor for me during this lockdown period.' The five points used to measure stressors were: 1-Never, 2-Often, 3-Sometimes, 4-Frequent, and 5-Always.

\subsubsection{Instrument Adopted to Identify Coping Strategies}

The brief COPE scale (abbreviated version with 28 items) was used to assess the coping strategies students adopted. Each item was captured using a four-point Likert-type scale ranging from 1, 'I have not been doing this at all.', to 4, 'I have been doing this a lot.' On this scale, a respondent choosing a higher score would mean that he or she had been resorting to a coping strategy more often. This scale had 14 dimensions, with each dimension having two indicator items, resulting in a total inventory of 28 items. These dimensions were active coping (items 2 and 7), denial (items 3 and 8), substance use (items 4 and 11), self-distraction (items 1 and 19), instrumental support (items 10 and 23), religion (items 22 and 27), behavioral disengagement (items 6 and 16), emotional support (items 5 and 15), planning (items 14 and 25), humor (items 18 and 28), acceptance (items 20 and 24), venting (items 9 and 21), positive reframing (items 12 and 17), and self-blame (items 13 and 26).

The reliability of this scale was found to range from 0.70 to 0.90 , which is acceptable for this purpose. In addition to the above scales, the instrument also had questions related to respondents' socio-demographic details. There was also a prerequisite question seeking willingness to participate in this survey. Therefore, only those respondents who answered 'yes' to the prerequisite question were emailed the questionnaire. Furthermore, all respondents were informed that their responses would be kept confidential and used only in aggregate form to understand the stated purpose. 


\subsection{Statistical Tools Used}

The analytics and research lab of, which has a licensed version of the data analysis software SPSS 22.0, was used to analyze the collected data. Respondents' demographic profiles were analyzed using basic frequencies and corresponding percentages. Furthermore, the basic descriptive statistical analysis of scale items was done using statistical measures such as mean, standard deviation, minimum, maximum, skewness, and kurtosis. To check the significant differences in the DASS scale responses based on demographic variables such as gender, type of program, and year of study in higher education, statistical tests such as an independent sample t test and one-way ANOVA were used.

\section{Results Analysis}

\subsection{Respondent Profiles}

In all, 235 students pursuing higher education submitted complete responses, which were used for further data analysis. Out of the 235 respondents, $59.15 \%$ (139) were male and $40.85 \%$ (96) were female. In terms of education, the participants pursuing an MBA, MCA, B.Tech, M.Tech, Ph.D., or other undergraduate courses were $25.96 \%$ (61), $11.49 \%$ (27), 42.98\% (101), 5.11\% (12), 2.98\% (7), and $11.49 \%$ (27), respectively. Finally, the participants included $61.28 \%$ (144) first-year students, $26.81 \%$ (63) second-year students, $8.09 \%$ (19) third-year students, and $3.89 \%$ (9) fourth-year students (Table 2).

Table 2 Demographic details of respondents

\begin{tabular}{llcc}
\hline Demographic variable & Levels & Frequency & $\begin{array}{l}\text { Frequency } \\
\text { percentage }\end{array}$ \\
\hline Gender & Male & 139 & 59.15 \\
& Female & 96 & 40.85 \\
Education & MBA & 61 & 25.96 \\
& MCA & 27 & 11.49 \\
& B.Tech & 101 & 42.98 \\
& M.Tech & 12 & 5.11 \\
& PhD & 7 & 2.98 \\
& Others & 27 & 11.49 \\
Year of study & 1st year & 144 & 61.28 \\
& 2nd Year & 63 & 26.81 \\
& 3rd Year & 19 & 8.09 \\
& 4th Year & 9 & 3.83 \\
\hline
\end{tabular}

*Total number of respondents $(n)=235$ 
Table 3 Overall results for depression, anxiety, and stress levels among students

\begin{tabular}{lcll}
\hline Severity level & Depression & Anxiety & Stress \\
\hline Males & & & \\
Normal & $45,(32.37 \%)$ & $51,(36.69 \%)$ & $37,(26.62 \%)$ \\
Mild & $65,(46.76 \%)$ & $67,(48.2 \%)$ & $55,(39.57 \%)$ \\
Moderate & $29,(20.86 \%)$ & $19,(13.67 \%)$ & $47,(33.81 \%)$ \\
Severe & $0,(0 \%)$ & $2,(1.44 \%)$ & $0,(0 \%)$ \\
Extremely severe & $0,(0(\%)$ & $0,(0 \%)$ & $0,(0 \%)$ \\
Females & & & \\
Normal & $9,(6.47 \%)$ & $7,(5.04 \%)$ & $10,(7.19 \%)$ \\
Mild & $23,(16.55 \%)$ & $35,(25.18 \%)$ & $23,(16.55 \%)$ \\
Moderate & $53,(38.13 \%)$ & $31,(22.3 \%)$ & $47,(33.81 \%)$ \\
Severe & $11,(7.91 \%)$ & $23,(16.55 \%)$ & $16,(11.51 \%)$ \\
Extremely severe & $0,(0 \%)$ & $0,(0 \%)$ & $0,(0 \%)$ \\
\hline
\end{tabular}

\begin{tabular}{lccc}
\hline Severity & Depression & Anxiety & \multicolumn{1}{l}{ Stress } \\
\hline Normal & $26,(11.06 \%)$ & $9,(3.83 \%)$ & $15,(6.38 \%)$ \\
Mild & $94,(40 \%)$ & $27,(11.49 \%)$ & $48,(20.43 \%)$ \\
Moderate & $114,(48.51 \%)$ & $121,(51.49 \%)$ & $134,(57.02 \%)$ \\
Severe & $1,(0.43 \%)$ & $78,(33.19 \%)$ & $38,(16.17 \%)$ \\
Extremely severe & $0,(0 \%)$ & $0,(0 \%)$ & $0,(0 \%)$ \\
\hline
\end{tabular}

Table 4 Results for depression, anxiety, and stress levels among male and female students 
Table 5 Results for depression, anxiety, and stress levels among male and female students

\begin{tabular}{lllllll}
\hline & Gender & Mean & SD & $T$ test & $p$ value & Decision \\
\hline Depression & Male & 14.338 & 3.601 & -2.257 & $0.025 ;>0.05$ & Significant \\
& Female & 15.438 & 3.769 & & & \\
Anxiety & Male & 12.719 & 2.998 & -7.413 & $0.000 ;>0.05$ & Significant \\
& Female & 15.854 & 3.443 & & & \\
Stress & Male & 12.129 & 3.033 & -8.319 & $0.000 ;>0.05$ & Significant \\
& Female & 15.552 & 3.195 & & & \\
\hline
\end{tabular}

levels of depression, $t(233)=-2.257, p>0.05$; anxiety, $t(233)=-7.413, p>0.05$; and stress, $t(233)=-8.319, p>0.05$, experienced by males and females. Furthermore, females with higher mean values for depression, anxiety, and stress experienced more depression, anxiety, and stress compared to their male counterparts.

The results of the one-way ANOVA at Alpha 5\% and F $(2,231)$ showed a significant difference in the mean values of depression, stress, and anxiety across students' current year of study (Table 6). In other words, the depression, anxiety, and stress levels of students in their first, second, third, and fourth year were significantly from each other in the calculated values for depression $[F(3,231)=5.102, p=0.002]$, anxiety $[F(3,231)=5.102, p=0.002]$, and stress $[F(3,231)=5.102, p=0.002]$.

The next objective of this study was to identify the most common causes of depression, anxiety, and stress among students pursuing higher education during the COVID-19 pandemic (Table 7).

A detailed literature review and in-depth interviews with 25 students were used to identify the most common stressors. Afterward, a 17-item questionnaire was

Table 6 Results for depression, anxiety, and stress levels among students studying in different years

\begin{tabular}{lllllll}
\hline & Year of study & Mean & SD & $\begin{array}{c}F \text { Statistics } \\
(\mathrm{d} f=3,231, \\
a=0.05)\end{array}$ & $p$ value & Decision \\
\hline Depression & 1st year & 14.451 & 3.812 & 5.102 & $0.002,<0.05$ & Significant \\
& 2nd year & 15.127 & 3.554 & & & \\
& 3rd year & 14.158 & 2.340 & & & \\
& 4th year & 19.111 & 2.472 & & & Significant \\
Anxiety & 1st year & 13.646 & 3.375 & 10.285 & $0.000 ;<0.05$ & \\
& 2nd year & 13.746 & 3.027 & & & \\
& 3rd year & 14.737 & 3.885 & & & \\
& 4th year & 19.889 & 3.723 & & & \\
Stress & 1st year & 13.472 & 3.474 & 9.528 & $0.000 ;<0.05$ & Significant \\
& 2nd year & 12.762 & 3.191 & & & \\
& 3rd year & 13.842 & 2.853 & & & \\
& 4th year & 19.111 & 3.180 & & & \\
\hline
\end{tabular}


Table 7 Results for most common stressors

\begin{tabular}{lcr}
\hline Sources of stress & Number & $\%$ \\
\hline Uncertainty about career in future & 197 & 83.83 \\
Change in daily routine & 177 & 75.32 \\
Financial problems & 155 & 65.96 \\
Not learning properly in online classes & 161 & 68.51 \\
Online exams & 165 & 70.21 \\
Exam result & 170 & 72.34 \\
Bad news & 140 & 59.57 \\
Problems in family & 122 & 51.91 \\
Problems in personal relationship (boyfriend or girlfriend) & 61.70 \\
Problem with roommate/s & 145 & 27.66 \\
Problems with friends in general & 65 & 23.83 \\
Problem with parents & 56 & 53.19 \\
Problem with the teacher & 125 & 42.98 \\
Living alone away from the family & 101 & 20.43 \\
Problem while sleeping & 48 & 31.91 \\
Pressure to get married & 75 & 8.94 \\
Lack of support from friends and family to solve problems & 21 & 37.02 \\
Unable to have my type of food & 87 & 41.28 \\
Low self-esteem & 97 & 29.36 \\
\hline
\end{tabular}

designed using a five-point Likert scale. This section of the questionnaire was tested for reliability using a Cronbach's Alpha value of 0.840 . The results are shown in Table 5, with the ten most common stressors being uncertainty about future career, change in daily routine, exam results, online exams, not learning properly in online classes, financial problems, problems in personal relationships, hearing bad news, problems with parents, and problems in the family.

\subsection{Coping Strategies}

This study also attempted to examine how students coped with depression, anxiety, and stress experienced during the lockdown period caused by the COVID-19 pandemic. To achieve this objective, the COPE scale (brief version) was used, and its results are displayed in Table 8.

The findings indicated major variations in male and female students' coping mechanisms for stress, anxiety, and depression, and are shown in Table 8. A onesample $t$ test (independent samples) was used to test for this. The COPE scale uses a four-point interval scale, meaning that scores over 2.5 indicate a higher degree of coping strategy use. As displayed in the above table, male students employed selfdistraction, behavioral disengagement, substance use, acceptance, planning, religion, positive reframing, humor, and instrumental support with respective mean scores of 
Table 8 Results for coping strategies of male and female students

\begin{tabular}{llllllll}
\hline COPE dimensions & Male & Females & SD (male) & SD (female) & $t$ & $p$ value & Decision \\
\hline Behavioral disengagement & 3.29 & 3.45 & 1.056 & 0.278 & -1.449 & 0.149 & Insignificant \\
Religion & 2.95 & 3.60 & 0.758 & 0.761 & -6.451 & 0.000 & Significant \\
Self-distraction & 3.40 & 3.10 & 1.125 & 0.442 & 2.482 & 0.014 & Significant \\
Acceptance & 3.11 & 2.98 & 0.066 & 1.127 & 1.358 & 0.176 & Insignificant \\
Planning & 3.11 & 2.88 & 1.351 & 0.891 & 1.462 & 0.145 & Insignificant \\
Use of instrumental sup- & 2.68 & 3.22 & 0.925 & 0.332 & -5.478 & 0.000 & Significant \\
$\quad$ port & & & & & & & \\
Humor & 2.78 & 2.97 & 0.044 & 1.337 & -1.676 & 0.095 & Significant \\
Positive reframing & 2.89 & 2.76 & 0.891 & 1.454 & 0.849 & 0.397 & Insignificant \\
Substance use & 3.29 & 2.25 & 1.088 & 0.559 & 8.610 & 0.000 & Significant \\
Use of emotional support & 2.34 & 3.10 & 1.009 & 0.998 & -5.701 & 0.000 & Significant \\
Venting & 2.56 & 2.87 & 1.364 & 0.768 & -2.016 & 0.045 & Significant \\
Active coping & 2.40 & 2.30 & 1.122 & 1.882 & 0.509 & 0.611 & Insignificant \\
Denial, items & 1.48 & 1.57 & 0.055 & 1.228 & -0.864 & 0.389 & Insignificant \\
Self-blame & 1.24 & 1.36 & 0.088 & 1.979 & -0.715 & 0.476 & Insignificant \\
\hline
\end{tabular}

3.40, 3.29, 3.29, 3.11, 3.11, 2.95, 2.89, 2.78, and 2.68. Denial and self-blame were the strategies male students used least often.

In contrast, female students employed religion, behavioral disengagement, instrumental support, emotional support, self-distraction, acceptance, humor, planning, venting, and positive reframing with respective mean scores of 3.60, 3.45, 3.22, $3.11,3.11,2.98,2.97,2.87$, and 2.78. Denial and self-blame were the strategies female students used least often, with mean scores of 1.57 and 1.36, respectively.

There were significant differences between the average scores of males and females in adopting coping strategies, including religion $t(233)=-6.451, p=0.000$, $p<0.05$; self-distraction $t(233)=2.482, p=0.014, p<0.05$; instrumental support $t(233)=-5.478, p=0.000, p<0.05$; humor $t(233)=-1.676, p=0.095$, $p<0.05$; substance use $t(233)=-8.610, p=0.000, p<0.05$; emotional support $\mathrm{t}(233)=-5.701, p=0.000, p<0.05 ;$ and venting $t(233)=-5.478, p=2.016$, $p<0.05$.

There were no significant differences in the mean scores for the other coping strategies.

\section{Discussion}

This study found that female students experienced more stress, anxiety, and depression than male students, which is consistent with earlier research. Recent studies have shown that women have higher chronic and everyday stress levels than men [45-47]. Moreover, Cahir and Morris (1991) found that the social, financial, and academic stressors of female students are greater than those of male students [48]. Another study indicated that females have higher stress levels and more health issues 
than males [49]. The high incidence of stress among women shows that women are more prone to stressful conditions. Women experience more stress because of socioeconomic difficulties, family ties, and educational constraints [49].

Furthermore, the incidence of depression is higher in women than in men [50]. Recent studies found that male and female students are statistically distinct in their sports skills. In general, men enjoy playing violent games like combat, while women use interpersonal strategies such as gossiping [51]. Many researchers have established that men typically display greater interest in sport than women, although others suggest that variances in sport behavior do not reflect fundamental interest variances [52]. The present study indicated that male and female students were statistically different in terms of their family relationships, with females' students being closer to their families than male students. According to previous studies, there are sex differences in emotional expression, with women being more expressive than men. The conceptualisation of sentiment involves manifold aspects, including 'a behavioral or expressive component, an experiential or verbal component, and a physiological component'. Some studies revealed that university students who have significant associations with family and friends are more likely to have overall life satisfaction [53]. One study regarding the coping mechanisms of students in a Pakistani medical college established that more than $90 \%$ of the students were facing a stressful situation during their academic days. The medical students used many coping techniques to combat stress, such as listening to music, playing sport, sleeping, and going into isolation [54]. Furthermore, some studies have found that continuous yoga practices help minimize the effect of depression in the lives of young adults [55].

Students have also been found to resort to coping mechanisms such as behavioral disengagement, becoming religious, self-distraction, instrumental support, planning, and acceptance, which align with earlier studies. Additionally, people can use relaxation, refuting illogical ideas, time management, assertiveness, maintaining good nutrition, exercising, changing their routines, and indulging in recreation to help them manage stress [56].

\section{Conclusion}

This study aimed to determine the stress, anxiety, and depression levels of students pursuing higher education in India during the ongoing COVID-19 pandemic, which has created an uncertain environment for students, teachers, and institutions alike. Students are worried about how they are going to learn and be assessed and hired in their industries when most businesses have virtually halted expansion plans and thus future recruitment. Moreover, many students' parents are struggling to pay tuition fees, as their incomes have been affected by the pandemic. From a teacher's standpoint, learning to plan and deliver lectures effectively online has been difficult. Although teachers are adapting slowly, online teaching effectiveness is far from benefiting students. Conducting assessments online has also been a major challenge, and poor infrastructure has made it virtually impossible to conduct proctored assessments on a large scale. 
All these factors have affected students psychologically, resulting in increased levels of stress, anxiety, and depression. This study found that $33 \%$ of students experienced severe anxiety, and $16 \%$ experienced severe stress during the pandemic. Furthermore, almost $85 \%$ of students experienced mild-to-moderate levels of depression, $62 \%$ experienced mild-to-moderate anxiety, and $77 \%$ experienced mildto-moderate stress levels during the pandemic.

Furthermore, this study found that male and female students varied significantly in their levels of stress, anxiety, and depression during the pandemic. Overall, female students experienced more anxiety, stress, and depression. Variations between students studying in different years were also significant. Stress, anxiety, and depression were greater in students in their final years of study, most likely because of uncertainty about their future.

Students resorted to different coping mechanisms such as behavioral disengagement, becoming religious, self-distraction, instrumental support, planning, and acceptance. Male and female students varied in their choice of coping mechanism for dimensions including religion, self-distraction, instrumental support, humor, and substance use. Females more often utilized religion, behavioral disengagement, instrumental support, emotional support, self-distraction, acceptance, humor, planning, venting, and positive reframing. Whereas male students more often used selfdistraction, behavioral disengagement, substance use, acceptance, planning, religion, positive reframing, humor, and instrumental support.

Although individuals believe that modern computer-aided technology has compressed the psychological workload, it has actually increased their psychological workload and further debilitated their social supports. Students who grew up in families lacking financial stability were more likely to show symptoms of depression and anxiety, indicating that financial difficulties correlate with higher rates of these mental health problems [57]. Grades, economic complications, professional future, lack of study time, an excessive workload, parental expectations of school performance, disagreement with friends, anguish with one's social life, and work-related problems are responsible for creating stress in life.

\section{Implications, Limitations, and Future Scope}

The life of a student is not always fulfilling for everyone. Being a student is stressful for most people because of numerous intrapersonal, interpersonal, academic, and environmental stressors. It is important to resolve these stressors with the correct approach and strategy. This study attempted to understand the levels of stress, anxiety, and depression experienced by students during the COVID-19 pandemic. It also reported what kinds of coping strategies students employed. Therefore, this study may be valuable to institutions, helping them devise strategies that align with students' expectations. Institutions may plan counseling sessions, organize recreational activities or yoga workshops, encourage students to play games, or plan online meditation sessions. Parents may also benefit from these findings, as they will better understand their children's problems and thus be better able to help them negotiate these difficult times. This study also adds to the existing body of knowledge related 
to stress, anxiety, and depression during the COVID-19 pandemic and thus is relevant to academics.

The present study's findings are based on a small sample of 235 students studying in higher education programs, including B.Tech, MBA, MCA, M.Tech, and $\mathrm{PhD}$ programs. These students were administered a questionnaire using a Google form. For these reasons, the present study cannot be generalized to people enrolled in MBBS, CA, BSc, or BA programs. Future research could expand this study to include other programs to make it more comprehensive. Also, this study might have yielded different results if the questionnaire was administered physically to respondents. Thus, future studies may wish to employ this method.

\section{Declarations}

Conflict of interest We hereby declare that this manuscript is an original work and is not under consideration for publication in any other journal. All authors have approved the submission of the manuscript the journal mentioned above.

\section{References}

1. Hui, D. S., Azhar, I. E., Madani, T. A., et al. (2020). The continuing 2019-nCoV epidemic threat of novel coronaviruses to global health-the latest 2019 novel coronavirus outbreak in Wuhan, China. International Journal of Infectious Diseases, 91(26), 264-266.

2. WHO Coronavirus Disease (COVID-19) Dashboard. https://covid19.who.int/. Accessed 21 Oct 2020

3. Burgess, S., \& Sievertsen, H. (2020). The impact of COVID-19 on education I VOX, CEPR Policy Portal. From https://voxeu.org/article/impact-covid-19-education. Accessed 21 Oct 2020

4. Burgess, S., \& Sievertsen, H. (2020). The long-term consequences of missing a term of school. From https://wol.iza.org/opinions/the-long-term-consequences-of-missing-a-term-of-school. Accessed 21 Oct 2020

5. Li, C., \& Lalani, F. (2020). The COVID-19 pandemic has changed education forever. This is how. In: World Economic Forum, vol 29

6. WHO (2020). Mental health and psychosocial considerations during the COVID-19 outbreak [Ebook]. Retrieved from https://www.who.int/docs/default-source/coronaviruse/mental-health-consi derations.pdf

7. Baxter, A. J., Charlson, F. J., Cheng, H. G., Shidhaye, R., Ferrari, A. J., \& Whiteford, H. A. (2016). Prevalence of mental, neurological, and substance use disorders in China and India: a systematic analysis. The Lancet Psychiatry, 3(9), 832-841.

8. Zhuo, L. B., Yao, W., Yan, Z., Giron, M. S., Pei, J. J., \& Wang, H. X. (2020). Impact of effort reward imbalance at work on suicidal ideation in ten European countries: the role of depressive symptoms. Journal of Affective Disorders, 260, 214-221. https://doi.org/10.1016/j.jad.2019.09.007

9. Roh, S. C., Kim, J. S., Kim, S., Kim, Y., \& Lee, S. H. (2020). Frontal alpha asymmetry moderated by suicidal ideation in patients with major depressive disorder: a comparison with healthy individuals. Clinical Psychopharmacology and Neuroscience, 18, 58. https://doi.org/10.9758/cpn.2020.18.1. 58

10. Rosal, M. C., Ockene, I. S., Ockene, J. K., Barrett, S. V., Ma, Y., \& Hebert, J. R. (1997). A longitudinal study of students' depression at one medical school. Academic Medicine, 72(6), 542-546.

11. Darling, C. A., McWey, L. M., Howard, S. N., \& Olmstead, S. B. (2007). College student stress: the influence of interpersonal relationships on sense of coherence. Stress and Health: Journal of the International Society for the Investigation of Stress, 23(4), 215-229.

12. Lyon, B. L. (2000). Stress, coping, and health. Handbook of stress, coping and health: Implications for nursing research, theory, and practice, 3-23 
13. Lazarus, R. S. (1991). Progress on a cognitive-motivational-relational theory of emotion. American Psychologist, 46(8), 819.

14. Aldwin, C. M., Sutton, K. J., \& Lachman, M. (1996). The development of coping resources in adulthood. Journal of Personality, 64(4), 837-871.

15. Spielberger, C. D. (2010). State-Trait anxiety inventory. The Corsini encyclopedia of psychology. New York: Wiley.

16. Firth-Cozens, J. (1987). Emotional distress in junior house officers. British Medical Journal (Clinical Research Edition), 295(6597), 533-536.

17 Vitaliano, P. P., Maiuro, R. D., Russo, J., \& Mitchell, E. S. (1989). Medical student distress: a longitudinal study. Journal of Nervous and Mental Disease, 177, 70.

18. Vitaliano, P. P., Russo, J., Carr, J. E., \& Heerwagen, J. H. (1984). Medical school pressures and their relationship to anxiety. Journal of Nervous and Mental Disease, 172, 730.

19. Antúnez, Z., \& Vinet, E. V. (2012). Escalas de depresión, ansiedad y Estrés (DASS-21): Validación de la Versión abreviada en Estudiantes Universitarios Chilenos. Terapia Psicologica, 30, 49-55. https://doi.org/10.4067/S0718-48082012000300005

20 Siegrist, J., \& Wege, N. (2020). Adverse psychosocial work environments and depression-a narrative review of selected theoretical models. Frontiers in Psychology. https://doi.org/10.3389/fpsyt. 2020.00066

21. Wang, C., Pan, R., Wan, X., Tan, Y., Xu, L., Ho, C., et al. (2020). Immediate psychological responses and associated factors during the initial stage of the 2019 coronavirus disease (COVID19) epidemic among the general population in China. International Journal of Environmental Research and Public Health, 17(5), 1729.

22. Goyal, K., Chauhan, P., Chhikara, K., Gupta, P., \& Singh, M. (2020). Fear of COVID 2019: first suicidal case in India. Asian Journal of Psychiatry, 49, 101989. https://doi.org/10.1016/j.ajp.2020. 101989

23. Mamun, M., \& Griffiths, M. (2020). First COVID-19 suicide case in Bangladesh due to fear of COVID-19 and xenophobia: Possible suicide prevention strategies. Asian Journal of Psychiatry, 51, 102073. https://doi.org/10.1016/j.ajp.2020.102073

24. Lazarus, R. S., \& Folkman, S. (1984). Stress, appraisal, and coping. Berlin: Springer.

25. Everley, M. J. (2002). The ethical aspects of risk assessment in the field of occupational safety and health. Doctoral dissertation, University of Leeds (Department of Philosophy)

26. Blake, R. L., \& Vandiver, T. A. (1988). The association of health with stressful life changes, social supports, and coping. Family Practice Research Journal

27 Mattlin, J. A., Wethington, E., \& Kessler, R. C. (1990). Situational determinants of coping and coping effectiveness. Journal of Health and Social Behavior, 31, 103-122.

28 Greenberg, S. F., \& Valletutti, P. J. (1980). Stress and the helping professions. Baltimore: PH Brookes.

29. Kumaraswamy, N. (2013). Academic stress, anxiety and depression among college students: a brief review. International Review of Social Sciences and Humanities, 5(1), 135-143.

30. Misra, R., \& McKean, M. (2000). College students' academic stress and its relation to their anxiety, time management, and leisure satisfaction. American Journal of Health Studies, 16(1), 41.

31. Towbes, L. C., \& Cohen, L. H. (1996). Chronic stress in the lives of college students: scale development and prospective prediction of distress. Journal of Youth and Adolescence, 25(2), 199-217.

32. Hurst, C. S., Baranik, L. E., \& Daniel, F. (2013). College student stressors: a review of the qualitative research. Stress and Health, 29(4), 275-285.

33. Whitman, N. A., Spendlove, D. C., \& Clark, C. H. (1984). Student stress: effects and solutions. ASHE-ERIC Higher Education Research Report No. 2

34. Acharya, S. (2003). Factors affecting stress among Indian dental students. Journal of Dental Education, 67, 1140-1148.

35. Pau, A., Rowland, M., Naidoo, S., et al. (2007). Emotional intel-ligence and perceived stress in dental undergraduates: a multinational survey. Journal of Dental Education, 71, 197-204.

36. Polychronopoulou, A., \& Divaris, K. (2005). Perceived sources of stress among Greek dental students. Journal of Dental Education, 69, 687-692.

37. Saxena, Y., Shrivastava, A., \& Singhi, P. (2014). Gender correlation of stress levels and sources of stress among first year students in a medical college. Indian Journal of Physiology and Pharmacology, 58, 147-151.

38. Tangade, P., Mathur, A., Gupta, R., et al. (2011). Assessment of stress level among dental school students: an Indian outlook. Dental Research Journal, 8, 95-101. 
39. Welle, P. D., \& Graf, H. M. (2011). Effective lifestyle habits and coping strategies for stress tolerance among college students. American Journal of Health Education, 42, 96-105. https://doi.org/ 10.1080/19325037.2011.10599177

40 Grover, S., Dutt, A., \& Avasthi, A. (2010). An overview of Indian research in depression. Indian Journal of Psychiatry. https://doi.org/10.4103/0019-5545.69231

41. Lopez, A. D., Mathers, C. D., Ezzati, M., Jamison, D. T., \& Murray, C. J. (2006). Global and regional burden of disease and risk factors, 2001: systematic analysis of population health data. The Lancet, 367(9524), 1747-1757.

42. Bandalos, D. L., Yates, K., \& Thorndike-Christ, T. (1995). Effects of math self-concept, perceived self-efficacy, and attributions for failure and success on test anxiety. Journal of Educational Psychology, 87(4), 611 .

43. Anspaugh, D. J., Hamrick, M. H., \& Rosato, F. D. (2003). Wellness: concepts and applications (5th ed.). McGraw-Hill.

44. Lovibond, P. F., \& Lovibond, S. H. (1995). The structure of negative emotional states: comparison of the depression anxiety stress scales (DASS) with the Beck depression and anxiety inventories. Behaviour Research and Therapy, 33(3), 335-343.

45. Hogan, J. M., Carlson, J. G., \& Dua, J. (2002). Stressors and stress reactions among university personnel. International Journal of Stress Management, 9(4), 289-310.

46. Ptacek, J. T., Smith, R. E., \& Zanas, J. (1992). Gender, appraisal, and coping: a longitudinal analysis. Journal of personality, 60(4), 747-770.

47. Tamres, L. K., Janicki, D., \& Helgeson, V. S. (2002). Sex differences in coping behavior: a metaanalytic review and an examination of relative coping. Personality and Social Psychology Review, 6(1), 2-30.

48. Cahir, N., \& Morris, R. D. (1991). The psychology student stress questionnaire. Journal of Clinical Psychology, 47(3), 414-417.

49. Hall, N. C., Chipperfield, J. G., Perry, R. P., Ruthig, J. C., \& Goetz, T. (2006). Primary and secondary control in academic development: gender-specific implications for stress and health in college students. Anxiety, Stress, and Coping, 19(2), 189-210.

50. Cyranowski, J. M., Frank, E., Young, E., \& Shear, M. K. (2000). Adolescent onset of the gender difference in lifetime rates of major depression: a theoretical model. Archives of General Psychiatry, 57(1), 21-27.

51. Benenson, A. J. (2016). 2 gossip, rumors, and social exclusion

52. Hogshead-Makar, N., \& Zimbalist, A. S. (Eds.). (2007). Equal play: title IX and social change. Philadelphia: Temple University Press.

53 Diener, E., \& Diener, M. (2009). Cross-cultural correlates of life satisfaction and self-esteem. In E. Diener (Ed.), Culture and well-being (pp. 71-91). Dordrecht: Springer.

54. Shaikh, B., Kahloon, A., Kazmi, M., Khalid, H., Nawaz, K., Khan, N., \& Khan, S. (2004). Students, stress and coping strategies: a case of Pakistani medical school. Education for Health: Change in Learning \& Practice, 17(3)

55. Woolery, A., Myers, H., Sternlieb, B., \& Zeltzer, L. (2004). A yoga intervention for young adults with elevated symptoms of depression. Alternative Therapies in Health and Medicine, 10(2), 60-63.

56. Miller, L. (2006). Psychological services, coping with stress. From http://www.temple.edu/couns eling/tipspy/stress1.html. Accessed 25 Aug 2006

57. Eisenberg, D., Gollust, S. E., Golberstein, E., \& Hefner, J. L. (2007). Prevalence and correlates of depression, anxiety, and suicidality among university students. American Journal of Orthopsychiatry, 77(4), 534-542.

Publisher's Note Springer Nature remains neutral with regard to jurisdictional claims in published maps and institutional affiliations. 